\title{
RECYCLE MATERIAL SEBAGAI MEDIA PEMBANGKIT MEMORI KOLEKTIF PADA BANGUNAN GEDUNG SERBAGUNA JEMA'AT AHMADIYAH INDONESIA
}

\author{
Intan Fitria Wardani ${ }^{1)}$, Suparwoko ${ }^{2)}$ \\ Mahasiswa Pendidikan Arsitek, Fakultas Teknik Sipil dan Perencanaan Universitas Islam \\ Indonesia ${ }^{1)}$ \\ Dosen Jurusan Arsitektur Fakultas Teknik Sipil dan Perencanaan Universitas Islam Indonesia \\ Universitas Islam Indonesia ${ }^{2)}$ \\ J1. Kaliurang No.Km. 14,5, Besi, Umbulmartani, Kec. Ngemplak, Kabupaten Sleman, Daerah \\ Istimewa Yogyakarta, Indonesia \\ Email: intanfitriaw@gmail.com ${ }^{1)}$
}

\begin{abstract}
ABSTRAK
Kenangan adalah memori yang akan menjadi cerminan manusia dalam menghadapi tantangan dimasa depan. Dalam proses pengingatan dan pelupaan memori, arsitektur menjadi tempat dimana memori kolektif dapat dirajut, tapi juga berperan dalam proses pelupaan. Tujuan dari penelitian ini yaitu untuk mengidentifikasi apakah penggunaan recycle material bangunan lama ke bangunan baru dapat membangkitkan memori kolektif Jema'at Ahmadiyah Indonesia. Bangunan lama pada penelitian ini adalah bangunan Arif Rahman Hakim yang akan segera dibongkar. Material bongkaran yang sudah diseleksi akan digunakan pada bangunan baru yang saat ini masih berupa rancangan Bangunan Serbaguna Jema'at Ahmadiyah Indonesia. Teknik pengumpulan data yaitu dengan melakukan wawancara mendalam, dokumentasi dan kajian teori. Tenik analisa dilakukan dengan menganalisa fakta-fakta yang didapat kemudian dikaitkan dengan aspek-aspek penting dari kajian teori. Hasil penelitian ini adalah penggunaan recycle material sebagai elemen bangunan baru belum berhasil dalam membangkitkan memori kolektif. Karena bentuk asli dari material bangunan tersebut memiliki perubahan yang signifikan. Hal yang membangkitkan memori dari para pengguna justru bukan dari materialnya melainkan dari bentuk ruang dan suasana ruang yang terbentuk.
\end{abstract}

Kata kunci: Bangunan lama, Bangunan baru, Kesan kesamaan, Memori kolektif, Recycle Material

\begin{abstract}
Memories are memory that will be a reflection of humans in facing challenges in the future. In the process of memory and memory forgetting, architecture becomes a place where collective memory can be knitted, but also plays a role in the process of forgetting. The purpose of this research is to identify whether the use of recycle of old building materials to new buildings can evoke the collective memory of the Ahmadiyya Community of Indonesia. The old building in this study is the Arif Rahman Hakim building which will be demolished soon. The dismantled material that has been selected will be used in the new building which is currently still in the form of the Ahmadiyya Congregation Versatile Building design. Data collection techniques are by conducting in-depth interviews, documentation and theoretical studies. Analysis technique is done by analyzing the facts obtained and then related to important aspects of the study of theory. The results of this study are that the use of recycle material as a new building element has not been successful in generating collective memory. Because the original shape of the building material has a significant change. The thing that evokes the memory of the users is actually not from the material but from the shape of the space and the atmosphere of the space that is formed.
\end{abstract}

Keyword: Collective memory, New building, Old building, Similarity impression, Recycle Material 


\section{PENDAHULUAN}

Memori secara alami berorientasi pada tempat (Hayden, 1995). Memori terbentuk dari kegiatan keseharian sebuah kelompok masyarakat yang saling berinteraksi dan terwadahi oleh arsitektur. Bagi Pallasmaa (2012) arsitektur sendiri memiliki arti sebagai eksternalisasi struktur mental manusia dan perpanjangan dari memori individu dan kolektif. Bangunan adalah instrument untuk meraih dan mempertahankan sejarah dan waktu yang analog dengan pemahaman sosial budaya. Karena itu, arsitektur tidak terlepas dari pemaknaan oleh berbagai pihak. Pemaknaan tersebut dapat berupa kegiatan yang melibatkan wacana pengingatan, pengabaian dan pelupaan.

Dalam proses pengingatan dan pelupaan memori, arsitektur menjadi tempat dimana memori kolektif dapat dirajut, tapi juga berperan dalam proses pelupaan. Dimana elemenelemen arsitektur digunakan untuk membangkitkan maupun melupakan memori. Contohnya, Gereja Santa Maria de Fatima yang terletak di Glodok, Jakarta, Gereja tersebut dimaknai bukan hanya sebagai tempat peribadatan, melainkan lebih dari itu sebagai arsip merawat memori kolektif identitas kelompok Tiong Hoa. Unsur-unsur pelestarian memori kolektif dapat dilihat dari bentuk material fisik dari arsitektur dan ornamen-ornamen yang mendominasi bangunan gereja tersebut. Ornamen dan gaya arsitektur khas Tionghoa dipertahankan agar para jemaat tetap mengenali identitas kultural dan memori akan kebudayaan tanah leluhur mereka.

Pada penelitian ini, objek yang akan akan diteliti adalah rancangan bangunan gedung serbaguna Jema'at Ahmadiyah Indonesia. Proyek desain ini dilatar belakangi dari rencana Organisasi Jema'at Ahmadiyah Indonesia (JAI) untuk membongkar salah satu bangunannya yang terletak di Jl. Atmosukarto no.15 Yogyakarta. Bangunan tersebut terdiri dari beberapa fungsi, yaitu perpustakaan Arief Rahman Hakim, masjid Fadhli Umar, dan guesthouse. Arsitektur dari bangunan tersebut memiliki nilai sejarah yang tinggi, karena merupakan hadiah dari Presiden Soekarno kepada Mubaligh JAI dalam peristiwa RIS.

Adapun gagasan dari arsitek yaitu untuk menggunakan kembali beberapa elemen bangunan yang dapat dimanfaatkan, seperti kusen-kusen pintu dan kusen jendela, daun pintu, daun jendela, serta elemen-elemen kayu yang dinilai masih layak untuk dapat digunakan kembali pada bangunan baru. Dalam perencanaan bangunan serbaguna Jema'at Ahmadiyah Indonesia, elemen bongkaran tersebut merupakan material yang akan digunakan pada bangunan tersebut sebagai elemen pembentuk ruang.

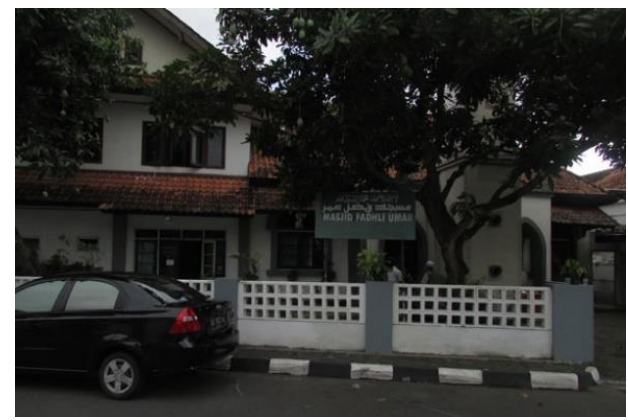

Gambar 1. Masjid Fadhil Umar Kota Baru

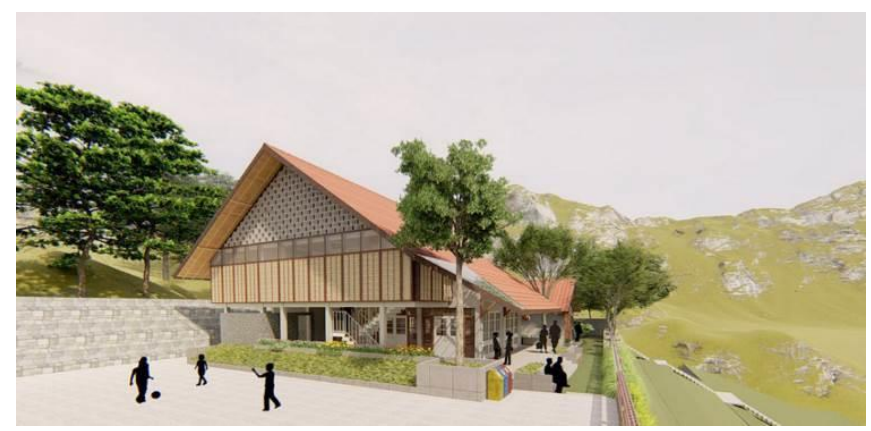

Gambar 2. Gambar Rancangan Bangunan Serbaguna Jema'at Ahmadiyah Indonesia di Piyungan 
Site terletak di kawasan dengan topografi berbukit di daerah Piyungan, Bantul. Dalam perancangan, bentuk bangunan menjadi fokus dalam pembentukan ruang-ruangnya. Bentuk bangunan dipengaruhi oleh bentuk dari elemen bangunan seperti pintu dan jendela yang direcycle menjadi bentuk yang baru. Elemen pintu dan jendela diletakkan di bagian fasade dan interior bangunan gedung Serbaguna.
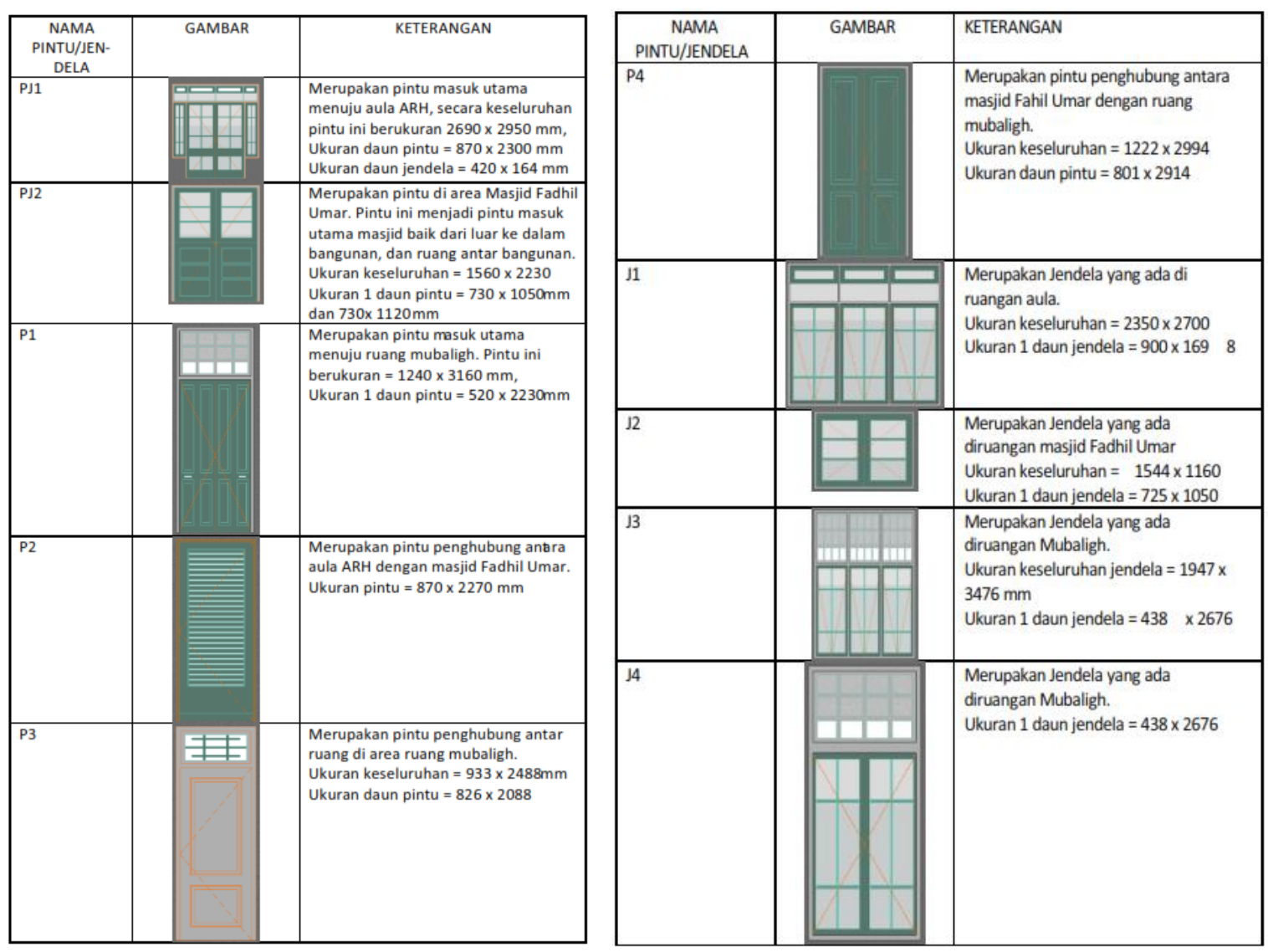

Gambar 3. Elemen Bangunan yang Akan Digunakan dalam Perancangan

Penelitian ini bertujuan untuk mengidentifikasi apakah penggunaan recycle material dari bangunan lama pada elemen bangunan baru dapat membangkitkan memori kolektif Jema'at Ahmadiyah Indonesia, dan mengidentifikasi peran penggunaan recycle material dalam mendukung reaksi pembangkitan memori dan pelupaan memori kolektif Jema'at Ahmadiyah Indonesia.

\section{TINJAUAN PUSTAKA}

\subsection{Tinjauan Sistem Memori pada Manusia}

Manusia melakukan proses mengingat dan menyimpan informasi dalam kehidupan sehari-harinya. Atkinson dan Shiffrin (Solso (1995) dalam Bhinnety (2008)) membagi struktur ingatan menjadi 3 bagian; yaitu sistem ingatan sensorik, sistem ingatan jangka pendek, sistem ingatan jangka panjang. Memori sensorik merupakan memori yang mencatat informasi atau rangsangan yang masuk melalui salah satu atau kombinasi dari panca indra, yaitu secara visual melalui mata, pendengaran melalui telinga, bau melalui hidung, rasa melalui lidah dan rabaan melalui kulit. Baddeley (1999) dalam Amalia 
(2011) menjelaskan bahwa Memori sensorik dipengaruhi oleh "memori ikonik" dan "memori pendengaran".

Baddeley (1999) dalam Amalia (2011) menjelaskan bahwa memori ikonik berkaitan dengan penyimpanan memori visual. Memori ikonik dipengaruhi oleh brightness dan contrast sehingga memori dapat menerima rangsang penglihatan (visual). Dalam ranah arsitektur, memori ikonik berkaitan dengan ingatan sebuah bentuk dan warna suatu benda. Sedangkan Memori pendengaran tidak mengingat hal-hal yang lebih menarik atau penting. Memori pendengaran akan menerima rangsangan suara.

\subsection{Tinjauan Memori Kolektif}

Memori kolektif sebagai salah satu simpul merupakan kondisi yang semakin memungkinkan keutuhan masyarakat karena adanya asal identitas yang sama. (the common source of identity). Halbwach (1980) dalam Wattimena (2016) menjelaskan, Memori kolektif sebuah kelompok masyarakat selalu diakui sebagai ingatan bersama. Artinya, semua anggota masyarakat mengetahui isi dari memori tersebut, dan mengakuinya sebagai versi yang sah. Memori kolektif semacam ini tertanam juga di daalam pikiran kolektif masyarakat tersebut sebagai sebuah kelompok, misalnya dalam bentuk berbagai monument dan cerita-cerita yang tersebar di masyarakat tentang masa lalu. Semua ini tersebar di masyarakat itu sendiri, dan diauku sebagai bagian dari identitas sosial kelompok masyarakat tersebut. Memori kolektif menggenggam makna kolektif atas sebuah peristiwa termasuk dengan symbol-simbolnya. Makna kolektif itu dapat merajai memori kolektif karena adanya berbagi pengalaman yang sama atau berkat proses sosialisasi. Sosialisasi ini dipelihara turun-temurun melalui perayaan, ritual-ritual, upacara-upacara, penulisan sejarah dan narasi dari mulut ke mulut (dalam masyarakat kuno) yang bertujuan untuk mengabadikan masa lalu. Proses ini dimulai dari unsur terkecil, yaitu individu. Pengalaman masing-masing individu menyebar ke komunitas dan tertanam sebagai memori kolektif dari penduduk suatu tempat. Maka, makna kolektif inilah yang lebih memainkan peranan dalam menjaga keutuhan masyarakat karena dihayati oleh masyarakat.

\subsection{Tinjauan Memori Kolektif pada Arsitektur}

Memori dan arsitektur merupakan hal yang tidak bisa dipisahkan. Saat seseorang membayangkan suatu tempat, maka kegiatan didalamnya juga akan terbayang dala pikiran kita. Kusno (2013) memiliki pendapat mengenai memori kolektif dalam ruang atau tempat yang lebih luas, yaitu ruang publik. Low dan Smith (2006) dalam Kusno (2013) ruang publik mencakup ruang fisik dan non fisik, seperti jalan, taman, media, internet, pusat perbelanjaan, pemerintah dan organisasi lingkungan lokal. Ia berpendapat bahwa memori kolektif dapat dirajut melalui proses pengingatan dan pelupaan melalui tatanan lingkungan fisik diruang publik melalui pemaknaan. Pemaknaan tersebut menjadikan ruang publik sebagai ruang yang aktif mengontrol dan membentuk kesadaran masyarakat.

Kusno (2013) mencoba melacak tipologi memori kolektif dengan mengamati perjalanan sejarah. Adapun tipologi memori kolektif berdasarkan penelitian Kusno (2013), yaitu: 
1) Memisahkan memori: Adanya wacana pelupaan dimana menjadikan ruang publik sebagai penanda perubahan jaman.

2) Mengatasi memori: Yaitu menciptakan ruang publik untuk mengingatkan kembali kepada masyarakat untuk tetap menatap masa depan tanpa harus dibebani masa lalu.

3) Penaklukan memori: Yaitu upaya penguasaan ruang publik dan adanya usaha memunculkan pelupaan terhadap memori.

4) Memasarkan memori: Yaitu usaha dalam membangkitkan kembali memori

5) Memori yang tak terwadahi: Memori yang tidak mendapatkan tempat diruang publik karena tidak sejalan dengan memori resmi.

\subsection{Tinjauan Memori Kolektif yang Dapat Membangkitkan Memori Kolektif}

Dalam pandangan yang lebih spesifik, Rossi (1984) menggambarkan cara pandang terhadap arsitektur, dimana arsitektur seharusnya bukan sebagai elemen yang mati, melainkan suatu elemen yang hidup atau dinamis. Ia beranggapan bahwa arsitektur dibentuk oleh memori, yaitu pecahan informasi yang didapat melalui senses yang dimiliki oleh tiap individu. Adanya hubungan yang dibentuk oleh tiap individu, menciptakan informasi atau memori yang dibentuk menjadi suatu memori kolektif. Memori kolektif menjadi suatu gagasan yang diproses sebagai pemikiran bersama oleh komunitas atau masyarakat. Hal ini menjadi dasar elemen-elemen dalam arsitektur, mulai dari struktur, fungsi, hingga bentuk bangunan. Bangunan yang dibentuk akan semakin banyak hingga membentuk suatu kampung, kemudian kampung tersebut semakin berkembang menjadi Kota.

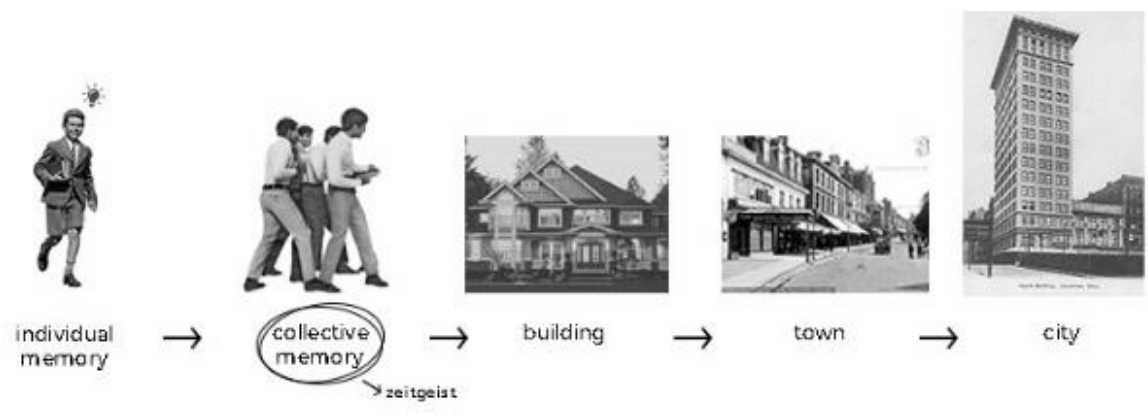

Gambar 4.Tinjauan Memori Kolektif

Arsitektur memungkinkan seseorang untuk memiliki pengalaman di tempat tersebut, dimana jika pengalamannya memiliki kesan yang penting, maka pengalaman tersebut akan menjadi sebuah memori. Individu-individu yang memiliki memori di suatu tempat akan teringat kembali pada memorinya ketika kembali ke tempat tersebut. Dalam hal ini, fungsi arsitektur merupakan sebuah pemicu membangkitkan memori.

\section{METODOLOGI PENELITIAN}

Penelitian ini bersifat kualitatif dengan metode indepth interview (wawancara mendalam). Pada penelitian ini, fakta-fakta diperoleh peneliti berkaitan dengan memori individual yang nantinya akan diolah menjadi sebuah memori kolektif terkait desain bangunan serbaguna Jema'at Ahmadiyah Indonesia yang berfokus pada recycle material. 
Sehingga penliti harus memiliki bekal teori dan wawasan mengenai memori kolektif dan parameter yang mempengaruhinya agar tujuan penelitian ini tercapai.

\subsection{Sumber Data}

Sumber data merupakan subjek dimana data-data diperoleh. Sumber data utama dalam penelitian kualitatif adalah kata-kata dan tindakan, selebihnya adalah data tambahan seperti dokumen dan lain-lain. Adapun sumber data yang digunakan dalam penelitian ini adalah:

1) Sumber Data Primer

Sumber data primer merupakan data yang diambil langsung oleh peneliti dari sumbernya tanpa ada perantara, dengan cara menggali sumber asli secara langsung melalui informan. Sumber data primer dari penelitian ini adalah anggota JAI (Ahmadi) yang tinggal atau menetap sementara di Yogyakarta.

2) Sumber Data Sekunder

Sumber data sekunder merupakan data tak langsung yang mampu memberikan tambahan serta penguatan data terhadap penelitian. Sumber data sekunder ini diperoleh melalui dokumentasi dan studi literature dari buku-buku, media cetak dan internet. Sumber data sekunder juga berupa foto-foto kegiatan yang diambil selama penelitian berlangsung. Sumber data dalam penelitian ini adalah bukubuku, jurnal, majalah, skripsi, dan foto-foto selama penelitian berlangsung.

\subsection{Teknik Sampling}

Menurut Sugiyono (2012), dalam penelitian kualitatif teknik sampling yang lebih sering digunakan adalah purposive sampling dan snowball sampling. Purposive sampling adalah teknik pengambilan sampel sumber data dengan pertimbangan tertentu. Snowball sampling adalah teknik pengambilan sampel sumber data yang pada awalnya jumlahnya sedikit, lama-lama menjadi besar.

Penelitian ini menggunakan teknik purposing sampling. Sampel yang dipakai untuk kemudian diambil datanya harus memenuhi kriteria:

1) Anggota Laki-laki juga sekaligus Mubaligh JAI yang tinggal lama di Yogyakarta.

2) Anggota laki-laki yang tinggal lama di Yogyakarta, dengan kategori umur lebih dari 40 tahun.

3) Anggota perempuan yang tinggal lama di Yogyakarta, dengan kategor umur lebih dari 40 tahun.

\subsection{Metode Analisis}

Analisa dilakukan dengan tujuan agar informasi yang dikumpulkan menjadi jelas. Dalam penelitian ini, teknik analisis yang digunakan adalah analisis model model interaktif. Miles dan Hubberman (1992) menjelaskan analisa ini terdiri dari 4 hal utama:

1) Pengumpulan Data

2) Reduksi Data

3) Penyajian Data 


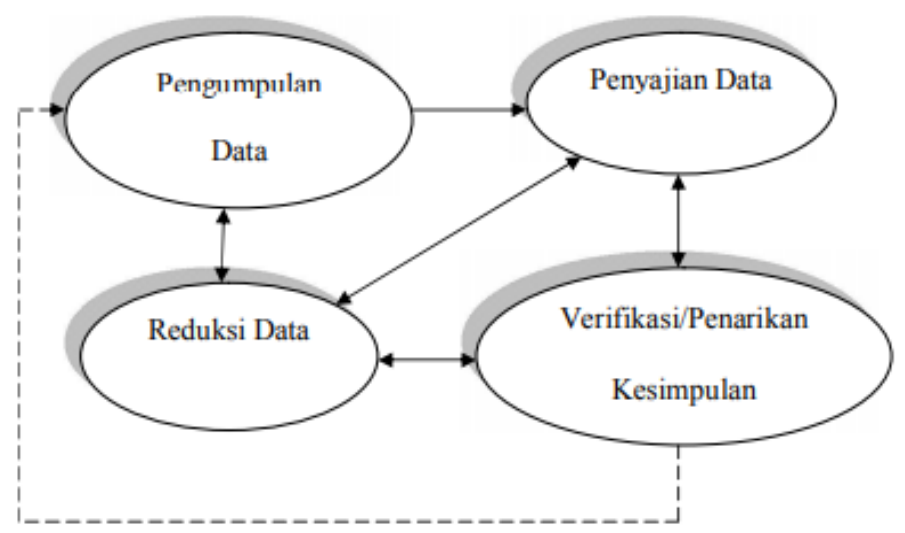

Gambar 5. Model Analisa Interaktif Miles dan Hubberman

\section{HASIL DAN PEMBAHASAN}

\subsection{Tinjauan Kesamaan Material antara Bangunan Lama dan Rancangan Bangunan Baru}

Adapun tujuan dari tinjauan similarity atau kesamaan antara material pada bangunan baru dan material pada bangunan lama, yaitu untuk membuat tool atau kriteria material yang dapat membangkitkan memori Jema'at pada bangunan Masjid, Aula yang terletak di Jl. Atmosukarto.

Tabel 1. Tinjauan Kesamaan Material pada Elemen Bangunan Lama dan Rancangan Bangunan Baru

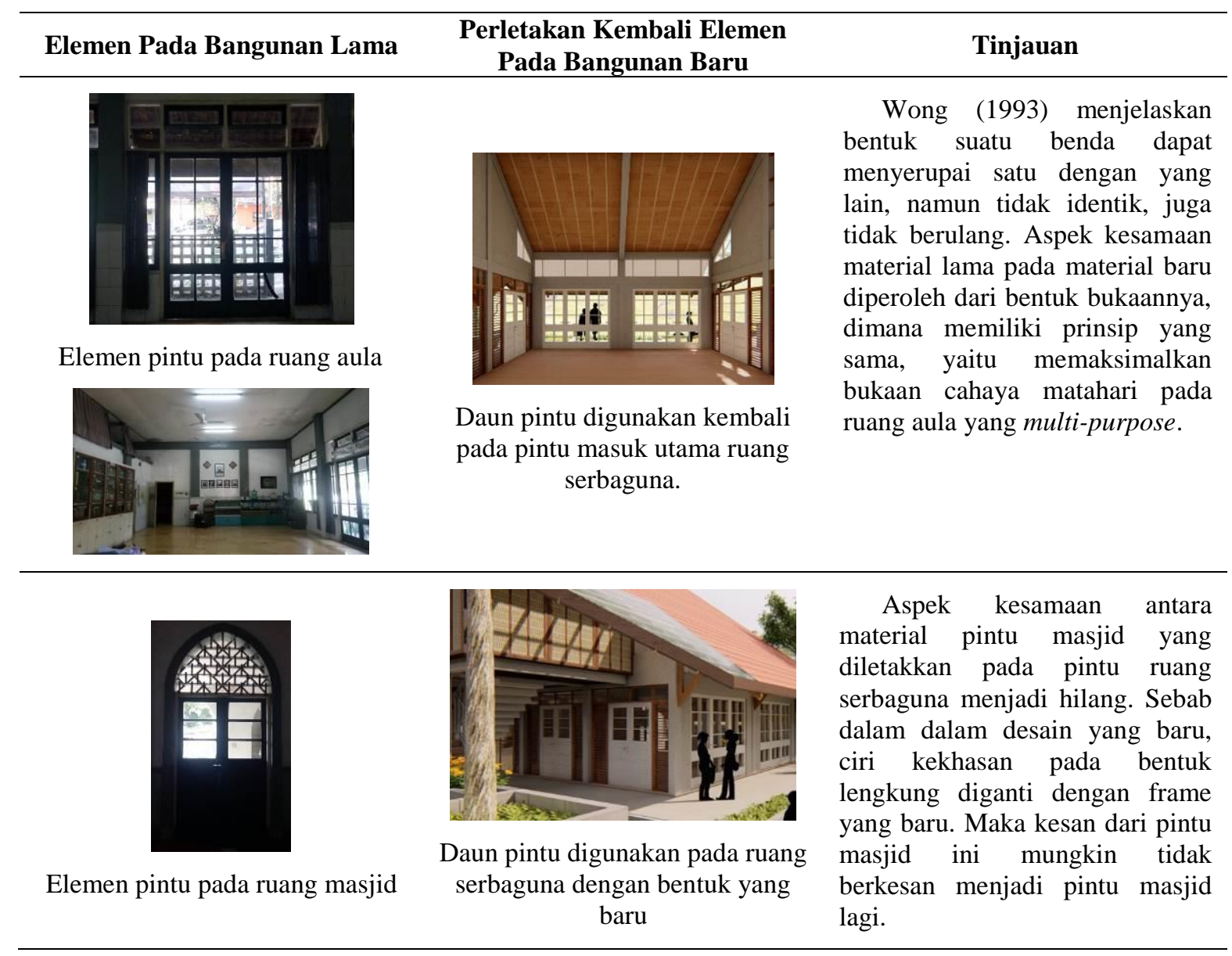




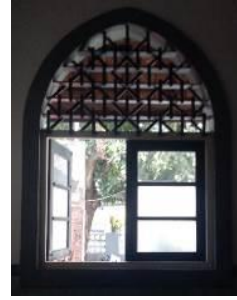

Elemen jendela pada ruang masjid

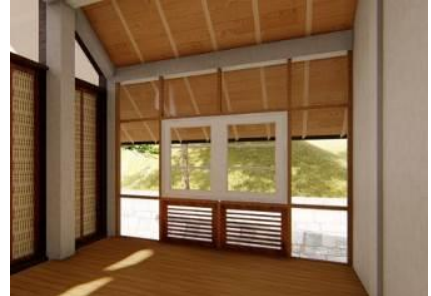

Daun pintunya digunakan kembali untuk pada ruang kantor dengan bentuk frame yang baru

Aspek kesamaan antara material jendela masjid yang diletakkan pada jendela ruang ruang kantor menjadi hilang. Sebab dalam desain yang baru, ciri kekhasan dari jendela masjid berupa lengkungan dan letak jendela yang berada diantara dinding masif ini diganti dengan frame yang transparan. Maka, jendela dari masjid ini akan kehilangan kesan jendela masjid Jema'at, karena bentuknya tidak menyerupai lagi atau tidak mirip.

Aspek kesamaan antara material jendela guesthouse yang diletakkan pada jendela rumah mubaligh menjadi hilang. Sebab dalam desain yang baru, ciri khas dari lubang ventilasi yang terkesan "jaman dulu" digantikan menjadi minimalis. Ukuran jendela juga tidak sama lagi. Maka jendela ini mungkin akan kehilangan kesannya.

Kusen dan daun pintunya

Pintu dan jendela dari ruang guest house digunakan kembali untuk rumah mubaligh

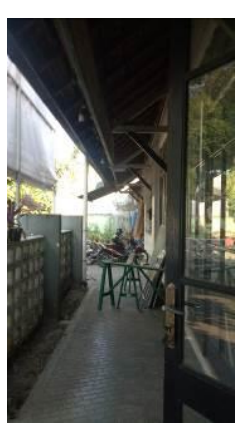

Konsol yang digunakan sebagai rangka untuk tritisan

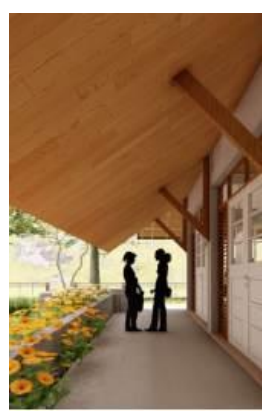

Konsol yang digunakan sebagai rangka untuk tritisan digunakan kembali dengan fungsi yang sama
Material konsol pada tritisan bangunan lama yang diterapkan dengan fungsi yang sama pada bangunan baru masih memiliki kesan kesamaan. Karena diletakkan pada selasar, dengan ketinggian yang sama dan ukuran selasar yang sama. Hal yang membedakan adalah warna dan finishingnya.

Berdasarkan tinjauan kesamaan tersebut, maka diperoleh instrumen gambar yang bisa dibandingkan untuk digali memorinya. Maka pernerapan material recycle yang masih memiliki kemiripan dengan material lama akan dijadikan alat untuk wawancara. Wawancara ini bertujuan untuk membuktikan bahwa material yang terseleksi memang dapat membangkitkan memori kolektif Jema'at akan bangunan Masjid dan Aula di Jl. Atmosukarto 
Tabel 2. Acuan Pertanyaan dalam Wawancara

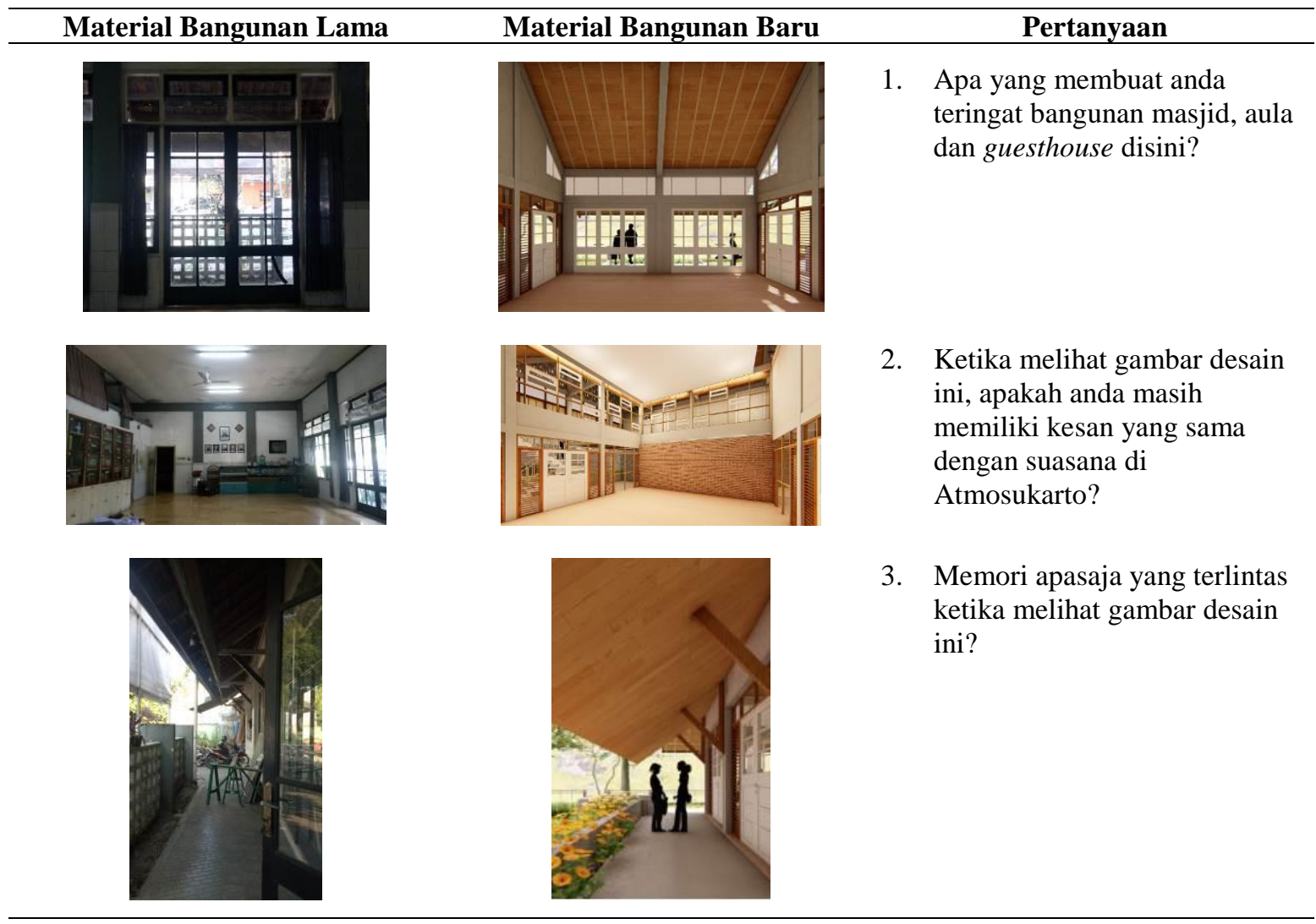

Narasumber dari penelitian ini adalah sebagai berikut:

1) Bapak Didit Hadi, 43 tahun, yaitu seorang Ahmadi keturunan yang menjabat sebagai Ketua Jema'at Ahmadiyah Indonesia.

2) Bapak Seno, 57 tahun, yaitu seorang anggota Jema'at yang dulunya seorang pengurus masjid Fadhil Umar.

3) Ibu Diah, 54 tahun, yaitu seorang tokoh organisasi perempuan (Lajnah Imaillah/LI), Beliau sejak lahir sudah berada di Yogyakarta dan menetap di daerah Baciro, dekat dengan Komplek masjid dan Aula J1. Atmosukarto.

4) Ibu Nurul Mukhlisah, 83 tahun, beliau adalah pensiunan yang dulunya merupakan pengajar. Beliau sudah lama tinggal di Yogyakarta.

5) Bapak Murtiono, 38 tahun, Beliau merupakan mubaligh Jema'at Ahmadiyah yang sedang bertugas di Yogyakarta. Beliau tinggal di kompleks masjid dan aula Jl. Atmosukarto selama 2 tahun.

6) Bapak Saifullah, 68 tahun, beliau merupakan anggota JAI, beliau adalah Dosen Arsitektur di UGM. Beliau termasuk orang yang mengembangkan kompleks Masjid dan Aula menjadi seperti saat ini

7) Bapak Nasir, beliau merupakan anggota JAI yang sudah lama tinggal di Yogyakarta. Beliau termasuk dalam anggota tertua di Yogyakarta.

8) Bapak Haryana, 75 tahun, beliau merupakan pensiunan dosen di UGM, yang pernah menjabat sebagai Ketua JAI Yogyakarta. Beliau termasuk orang yang mengembangkan kompleks Masjid dan Aula menjadi seperti saat ini. 
9) Bapak Tomo, 75 Tahun, Beliau merupakan penggerak organisasi yang ada di Pangol, Piyungan.

\subsection{Pembahasan Hasil Wawancara}

Tabel 3. Penelusuran Memori Kolektif Jema'at Ahmadiyah Indonesia pada Bangunan Masjid dan Aula Kota Baru

\begin{tabular}{|c|c|c|c|c|}
\hline $\begin{array}{c}\text { DAFTAR } \\
\text { PERTANYAAN }\end{array}$ & $\begin{array}{c}\text { NARASUMBER } 1 \\
\text { (Bapak Didit) }\end{array}$ & $\begin{array}{c}\text { NARASUMBER } 2 \\
\text { (Bapak Seno) }\end{array}$ & $\begin{array}{c}\text { NARASUMBER } 3 \\
\text { (Ibu Diah) }\end{array}$ & $\begin{array}{l}\text { NARASUMBER } 4 \\
\text { (Bapak Mutiyono) }\end{array}$ \\
\hline $\begin{array}{l}\text { Hal apa yang membuat } \\
\text { anda teringat pada } \\
\text { bangunan masjid dan } \\
\text { aula disini? }\end{array}$ & $\begin{array}{l}\text { Bangunan Masjid dan } \\
\text { aula disini punya fungsi } \\
\text { sejarah. Terutama } \\
\text { sejarah pengakuan } \\
\text { keberadaan } \\
\text { kelembagaan } \\
\text { Ahmadiyah. Jadi ada } \\
\text { fungsi perjuangan untuk } \\
\text { bisa mendapatkan } \\
\text { bangunan ini. Kalau } \\
\text { secara pribadi, masjid } \\
\text { itu adalah tempat } \\
\text { pertama kali saya } \\
\text { belajar mengaji sekitar } \\
\text { TK, baru sekitar SMA } \\
\text { saya ke Jogja lagi, } \\
\text { bangunan ini (aula) } \\
\text { berdiri. Kalau dari } \\
\text { fungsi bangunan masjid } \\
\text { digunakan sebagai } \\
\text { masjid, kita lebih ke } \\
\text { fungsi ibadah. Secara } \\
\text { pribadi saya sudah ke } \\
\text { banyak masjid dari } \\
\text { masjid Ahmadiyah dan } \\
\text { yang bukan milik } \\
\text { Ahmadiyah, tetapi tetap } \\
\text { ada rasa nyaman di } \\
\text { masjid ini, ya karena } \\
\text { ada fungsi historis. }\end{array}$ & $\begin{array}{l}\text { Saya datang kesini } \\
\text { sudah seperti ini, Cuma } \\
\text { yang saya dengar dari } \\
\text { cerita dari orang yang } \\
\text { terlibat dari yang dulu } \\
\text { disini, adalah rumah } \\
\text { asli adalah rumah } \\
\text { yang ditempati Bapak } \\
\text { Mubaligh, kemudian } \\
\text { dibangun masjid, } \\
\text { kemudian aula dan } \\
\text { terakhir dibangun lantai } \\
\text { 2. Saya sudah } 10 \text { tahun } \\
\text { sudah disini, setiap hari } \\
\text { disini, mengurus disini. }\end{array}$ & $\begin{array}{l}\text { Dulu sebenarnya tanah } \\
\text { ini dihibahkan dari } \\
\text { Presiden Sukarno } \\
\text { sebagai tanda } \\
\text { terimakasih kepada } \\
\text { Mubaligh Ahmadiyah } \\
\text { yang saat itu bertugas di } \\
\text { Yogyakarta. Beliau ikut } \\
\text { menerjemahkan } \\
\text { proklamasi Indonesia } \\
\text { ke dalam Bahasa Arab } \\
\text { dan Bahasa Inggris } \\
\text { tentang kemerdekaan } \\
\text { Indonesia. } \\
\text { Dulu semasa TK, ya } \\
\text { sekitar tahun 70an, } \\
\text { kemudian saya SD } \\
\text { tahun } 72 \text { itu sudah aktif } \\
\text { disini untuk ngaji. Ada } \\
\text { TPA disini Minggu pagi } \\
\text { atau sore, dulu yang } \\
\text { mengajar adalah } \\
\text { khuddam khuddam } \\
\text { yang mengajar ngaji } \\
\text { disini. Yang ikut ngaji } \\
\text { itu nggak banyak, yaa } \\
\text { yang sepantaran saya } \\
\text { anak-anak TK gitu yang } \\
\text { tinggal disekitar sini. }\end{array}$ & $\begin{array}{l}\text { Masjid ini dibangun } \\
\text { bersama-sama. Lokasi } \\
\text { ini dihadiahi oleh Bung } \\
\text { Karno, saya kurang } \\
\text { tahu apakah ini asset } \\
\text { atau bukan, Dari } \\
\text { referensi yang pernah } \\
\text { saya baca, bahwa Bung } \\
\text { Karno meminta HB ke } \\
\text { IX waktu itu untuk } \\
\text { memberikan lahan ini } \\
\text { kepada Jema'at, lalu } \\
\text { diberikan, sebagai } \\
\text { sebagai bukti hadiah } \\
\text { dari pemerintah karena } \\
\text { jasa dari Mubaligh } \\
\text { Ahmadiyah, waktu itu } \\
\text { Syaikh Syah } \\
\text { Muhammad sebagai } \\
\text { salah seorang pejabat } \\
\text { tinggi di era bung } \\
\text { Karno, karena beliulah } \\
\text { juga propaganda di } \\
\text { Indonesia ini sampai ke } \\
\text { Internasional. Sehingga } \\
\text { mendapat dukungan } \\
\text { dari India, Paksitan. } \\
\text { Sehingga ya secara } \\
\text { aklamasi secara } \\
\text { pemerintah ya } \\
\text { diberikan, tetapi ya } \\
\text { biaya administrasi dan } \\
\text { surat-surat. Waktu itu } \\
\text { ada anggota dari } \\
\text { Padang yang sedang } \\
\text { berada di Semarang. }\end{array}$ \\
\hline KATA KUNCI & $\begin{array}{l}\text { 1. Sejarah perjuangan } \\
\text { keberadaan } \\
\text { Kelembagaan } \\
\text { Ahmadiyah di } \\
\text { Yogyakarta } \\
\text { 2. Sejarah bangunan } \\
\text { 3. Aktivitas/dinamika } \\
\text { kegiatan } \\
\text { keagamaan }\end{array}$ & $\begin{array}{l}\text { Sejarah perjuangan } \\
\text { keberadaan } \\
\text { Kelembagaan } \\
\text { Ahmadiyah di } \\
\text { Yogyakarta }\end{array}$ & $\begin{array}{l}\text { Aktivitas/dinamika } \\
\text { kegiatan keagamaan }\end{array}$ & $\begin{array}{l}\text { Sejarah perjuangan } \\
\text { keberadaan } \\
\text { Kelembagaan } \\
\text { Ahmadiyah di } \\
\text { Yogyakarta }\end{array}$ \\
\hline
\end{tabular}

\begin{tabular}{|c|c|c|c|c|}
\hline $\begin{array}{c}\text { NARASUMBER } 9 \\
\text { (Bapak TOMO) }\end{array}$ & $\begin{array}{c}\text { NARASUMBER } 5 \\
\text { (Bapak Saifullah) }\end{array}$ & $\begin{array}{c}\text { NARASUMBER } 6 \\
\text { (Bapak Haryana) }\end{array}$ & $\begin{array}{c}\text { NARASUMBER } 7 \\
\text { (Ibu Nurul) }\end{array}$ & $\begin{array}{c}\text { NARASUMBER } 8 \\
\text { (Bapak NASIR) }\end{array}$ \\
\hline $\begin{array}{l}\text { Mengenai masjid, masjid } \\
\text { merupakan salah satu } \\
\text { kunci yang amat sangat } \\
\text { penting, maka dari nuansa } \\
\text { masjid yang di kota baru } \\
\text { yang pernah saya cermati. } \\
\text { JAI itu } \\
\text { perkembangannya susah } \\
\text { itu. karena semua teman- } \\
\text { teman muslim itu } \\
\text { memusuhi. Faktanya } \\
\text { seperti itu. }\end{array}$ & $\begin{array}{l}\text { Sebagai perancang } \\
\text { bangunan anda pasti } \\
\text { harus punya konsep } \\
\text { filosofis. Konsep } \\
\text { filosofis itu sebagai } \\
\text { grand concept. Satu } \\
\text { moto yang ada di } \\
\text { jema'at adalah } \\
\text { Rahmatan lil alamin, } \\
\text { dalam Bahasa Jawanya } \\
\text { (sambal bercanda) } \\
\text { "Love for all, Hatred } \\
\text { for none". }\end{array}$ & $\begin{array}{l}\text { Pada waktu } \\
\text { membangun ini, saya } \\
\text { kira belum ada refensi } \\
\text { menara dan bentuk- } \\
\text { bentuk dari masjid } \\
\text { Jema'at. }\end{array}$ & $\begin{array}{l}\text { Semasa kecil dulu, } \\
\text { disini selalu diadakan } \\
\text { pengajian TPA, dulu } \\
\text { karena disini masjid } \\
\text { satu-satunya jadi masjid } \\
\text { ini selalu ramai ketika } \\
\text { waktu sholat. }\end{array}$ & $\begin{array}{l}\text { Ya saya dulu termasuk } \\
\text { anggota yang aktif } \\
\text { dalam kegiatan } \\
\text { organisasi, ya karena } \\
\text { sekarang saya sudah } \\
\text { tua, jadi sudah tidak } \\
\text { lagi akrif. Tapi saya } \\
\text { masih bersemangat } \\
\text { ketika ada yang tertarik } \\
\text { dengan Ahmadiyah. } \\
\text { Kenangan saya yang } \\
\text { paling melekat, ketika } \\
\text { itu saya termasuk dalam }\end{array}$ \\
\hline
\end{tabular}




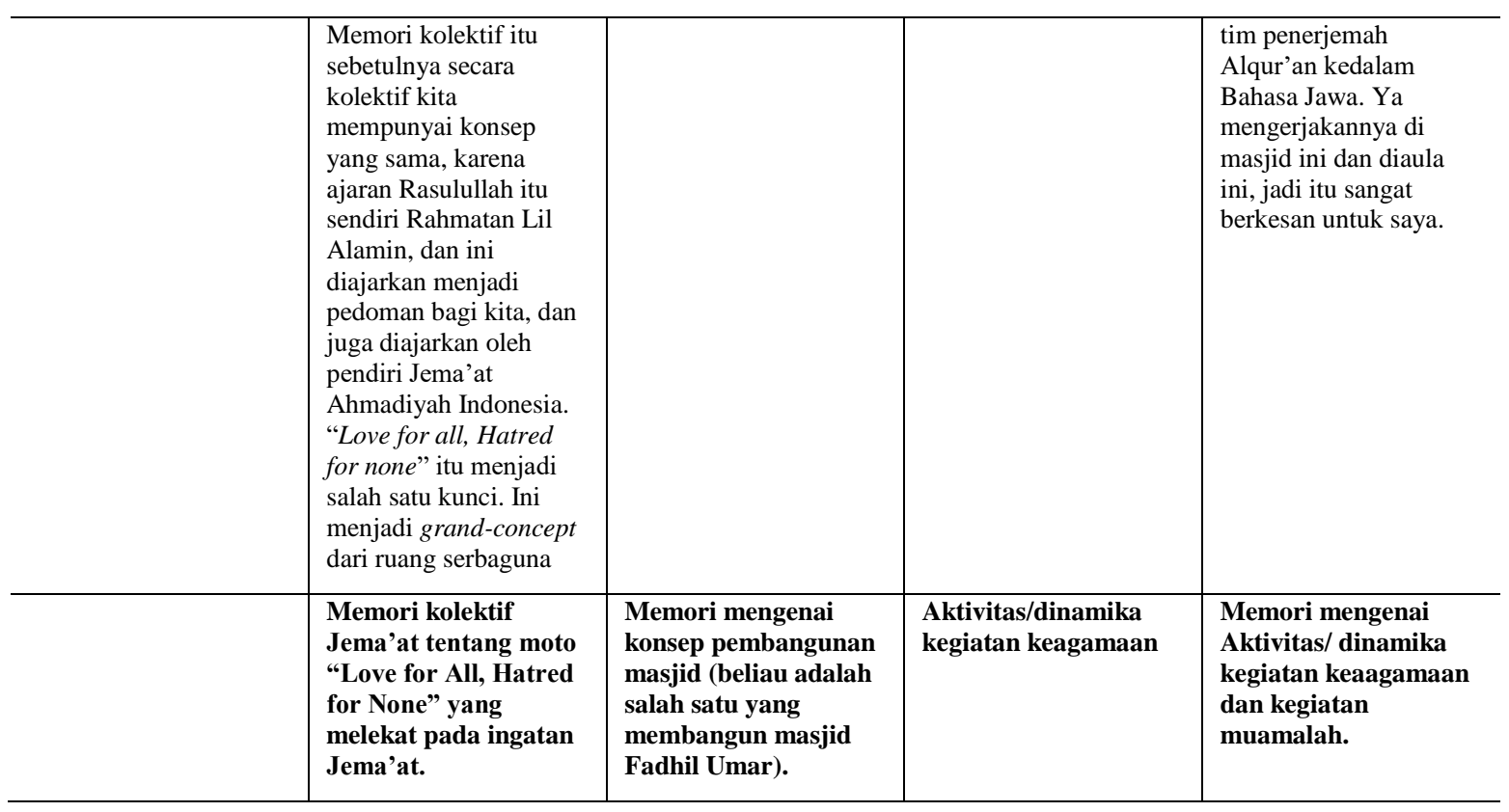

Tabel 4. Tabel Penelusuran Material yang Dapat Membangkitkan Memori pada Bangunan Masjid dan Aula Kotabaru

\begin{tabular}{|c|c|c|c|c|}
\hline $\begin{array}{c}\text { DAFTAR } \\
\text { PERTANYAAN }\end{array}$ & $\begin{array}{l}\text { NARASUMBER } 1 \\
\text { (Bapak Didit) }\end{array}$ & $\begin{array}{c}\text { NARASUMBER } 2 \\
\text { (Bapak Seno) }\end{array}$ & $\begin{array}{c}\text { NARASUMBER 4 } \\
\text { (Bapak } \\
\text { Mutiyono) }\end{array}$ & $\begin{array}{c}\text { NARASUMBER } 3 \\
\text { (Ibu Diah) }\end{array}$ \\
\hline \multicolumn{5}{|l|}{$\begin{array}{l}\text { Apaka ada kesamaan } \\
\text { dari ruangan ini } \\
\text { dengan bangunan di } \\
\text { Kotabaru? } \\
\end{array}$} \\
\hline At $\rightarrow=1$ & $\begin{array}{l}\text { Kalau ini ditransfer kesini, } \\
\text { ini berbeda sekali. Pintu } \\
\text { ini vital untuk membuat } \\
\text { kesan mirip dengan } \\
\text { masjid. Suasana masjid } \\
\text { ini memang sudah sangat } \\
\text { kuno, namun pada desain } \\
\text { anda memberikan kesan } \\
\text { yang baru dengan } \\
\text { menghadirkan pintu } \\
\text { masjid dengan frame } \\
\text { pintu aula. Tapi memang } \\
\text { agak sulit untuk } \\
\text { menghadirkan suasana } \\
\text { masjid. Bentuk lubang- } \\
\text { lubang ini yang mungkin } \\
\text { akan lebih menghadirkan } \\
\text { suasana masjid. }\end{array}$ & $\begin{array}{l}\text { Ya menurut saya ini agak } \\
\text { mirip, ya karena nuansa dari } \\
\text { bentuk bangunannya } \\
\text { (bukaan). }\end{array}$ & & $\begin{array}{l}\text { Aku kok nggak bisa } \\
\text { ngelihat kemiripan, ya } \\
\text { karena jendela- } \\
\text { jendelanya sudah } \\
\text { gak mirip. Kalau } \\
\text { menurut sih kurang } \\
\text { membawa.. karena } \\
\text { disini plafonnya lebih } \\
\text { pendek dan yang } \\
\text { didesain ini plafonnya } \\
\text { tinggi. Ya kurang si } \\
\text { mbak. } \\
\text { Kalau masjid disini } \\
\text { menruut saya desainnya } \\
\text { kuno. Terus disini } \\
\text { juga desain mbaknya } \\
\text { pakai kayu, kesannya } \\
\text { mewah, kemudian } \\
\text { pencahayaannya } \\
\text { banyak, dan lebih rapi. }\end{array}$ \\
\hline $\begin{array}{c}\text { Material yang } \\
\text { dimaksud }\end{array}$ & (1) & $\begin{array}{l}\text { Nuansa yang dimaksud } \\
\text { adalah kualitas ruangnya, } \\
\text { seperti memiliki bukaan } \\
\text { pintu dan jendela yang } \\
\text { lebar. }\end{array}$ & & IF \\
\hline
\end{tabular}




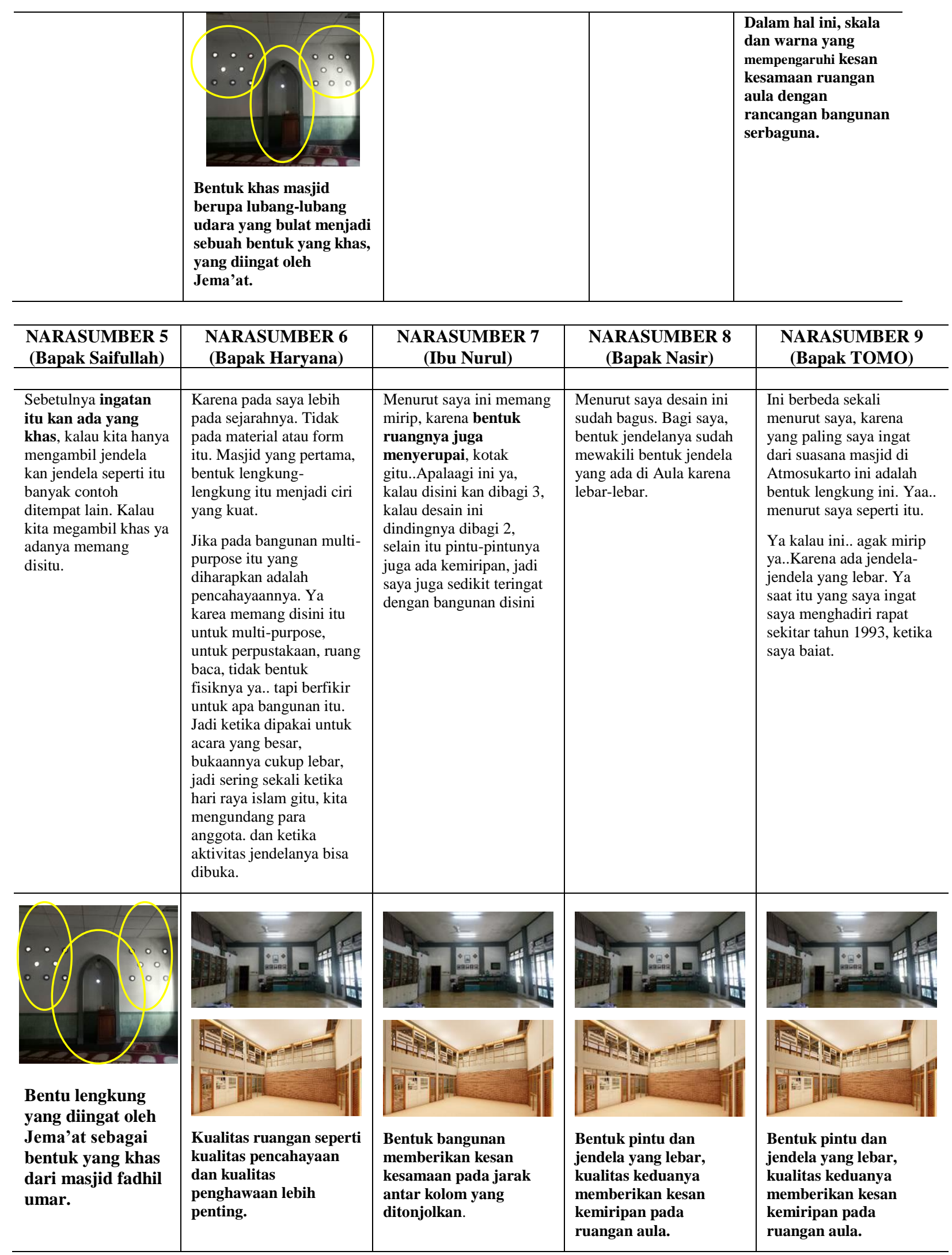

Berdasarkan rangkuman wawancara pada tabel 4, terdapat poin-poin penting yang bisa diambil untuk dibandingkan dengan teori menegenai arsitektur sebagai pemicu memori. Diantaranya adalah: 
1) Kesan Kemiripan terhadap bentuk yang khas dari material.

2) Kesan Kemiripan terhadap warna material.

3) Kesan Kemiripan terhadap dimana material tersebut diletakkan.

4) Kesan Kemiripan dengan skala ruangnya.

Dari keempat kata kunci tersebut kemudian akan dicocokkan dengan dasar teori dari arsitektur yang dapat memicu memori kolektif. Kemiripan terhadap bentuk dan warna yang khas dari material merupakan aspek yang paling penting, berkaitan dengan memori ikonik, dimana seseorang akan mudah mengingat dari bentuk dan warna yang lebih mencolok dari bentuk lainnya.

Perletakan kembali material elemen bangunan pada letak awalnya sedikit memberikan gambaran dari masa lalu. Ketika sebuah pintu aula diletakkan pada bagian depan ruang serbaguna, para narasumber akan tersadar bahwa pintu tersebut dulunya adalah bagian dari pintu aula tempat mereka beraktivitas. Namun, ketika suasana ruang dibuat mirip, dengan diberikan bukaan-bukaan yang lebar seperti pada suasana aula terdahulu, maka perletakan kembali material tidak menjadi penting. Melainkan bentuk khas dari bukaan tersebut yang akan membawa suasana ruang kembali. Seperti bentuk pintu masjid yang khas dengan bentuk lingkarnya. Dalam hal ini sesuai dengan teori DK Ching (1996), Dimana elemen arsitektur dapat dilihat secara visual melalui bentuk, skala, warna, tekstur maupun materialnya.

Penggunaan material yang di recycle, dimana material tersebut di daur ulang dari segi bentuk, warna letak. dan ukurannya semua berbeda, justru akan menghilangkan memori pengguna terhadap material tersebut, juga kesan akan ruangan sebelumnya menghilang. Menurut Kusno, memori kolektif dapat dirajut melalui proses pengingatan dan pelupaan melalui tatan lingkungan fisik diruang publik melalui pemaknaan. Maka pemaknaan itu sendiri menjadi aspek yang terpenting karena pemaknaan menjadikan ruang tersebut aktif mengontrol dan membentuk kesadaran masyarakat. Artinya, memori kolektif melalui pemaknaan ini, menjadi lebih kuat daripada melihat dengan wujud fisiknya.

Dari bahasan tersebut, maka pertanyaan selanjutnya adalah bagaimana Jema'at memaknai bangunan mereka sendiri terutama pada bagunan Ahmadiyah?

Salah satu tokoh Mubaligh Jema'at, Bapak Murtiyono menjelaskan bahwa:

"Bangunan itu memiliki misi perdamaian, siapapun yang masuk harus merasa nyaman. Bangunan yang ada dijemaat entah itu masjid, guest house atau fasilitas lain diharapkan dapat menjadi pusat dari kegiatan masyarakat, apapun itu, terutama untuk pendidikan, pengembangan pengetahuan, hubungan sosial dan hubungan-hubungan keumatan"

Bapak Tomo, salah satu tokoh yang ada di Pangol Piyungan, menjelaskan bahwa masjid merupakan salah satu kunci yang amat sangat penting. Beliau menganggap masjid seperti kerajaan ruhani, dimana di masjid beliau dapat beribadah dan merasa tentram didalamnya.

Bapak Seno, yang dulunya merupakan penjaga bangunan masjid Fadhil Umar, mengatakan:

"Saya sudah 10 tahun sudah disini, setiap hari disini, mengurus disini. Disini strategis, karena banyak tamu, ya banyak tamu intern dari jema'at dan tamu dari luar. 
Kalau tamu intern bisa ditempatkan di guesthouse lantai 2, asalnya jauh-jauh, banyak yang dari Jakarta, Kalimantan, Sumatra bahkan Irian, Sulawesi. Ya kalau anggota banyak dari seluruh Indonesia, kalau ke kota ini ya menginap di masjid jema'at. Misalnya saya ke Jakarta, saya ngga perlu nyari-nyari hotel, ya saya perlu mencari masjid-masjid Ahmadiyah yang paling dekat. Karena standarnya pelayanan tamunya sama. Biasayanya masjid Ahmadiyah ada masjidnya, rumah misi dan guesthouse. Rumah misi itu adalah rumah yang ditinggali oleh mubaligh gitu."

Penjelasan diatas menujukkan pemaknaan mengenai bangunan milik Jema'at Ahmadiyah, dimana bangunan tersebut selalu digunakan dalam berbagai aktivitas ibadah, tabligh dan kelembagaan. Pemaknaan tersebut sesuai dengan slogan mereka, yaitu "Love for All, Hatred for None". Slogan ini menjadi simbol Jema'at Ahmadiyah, meskipun bukan simbol yang dapat dilihat secara fisik.

\section{KESIMPULAN}

Dari hasil pembahasan tentang recycle material sebagai pembangkit memori kolektif, dapat disimpulkan bahwa penggunaan material yang di recycle, dimana material tersebut di daur ulang dari segi bentuk, warna dan ukurannya, justru akan menghilangkan memori pengguna terhadap material tersebut, juga kesan akan ruangan sebelumnya menghilang. Perubahan bentuk, warna dan ukuran pada elemen bangunan seperti pintu dan jendela disini berubah secara signifikan.

Kesan kemiripan akan muncul dalam persepsi seseorang apabila perubahan bentuk, warna dan ukuran tidak terlalu banyak berubah, atau arsitek dapat menangkap hal yang menjadi ciri khas dari bangunan tersebut, kemudian dimunculkan kembali kedalam desain menurut bentuk, warna maupun ukurannya.

Memori kolektif muncul dari pemaknaan para narasumber akan bangunannya, bukan dari jenis materialnya. Adapun memori kolektif yang disepakati oleh Jema'at adalah masjid dan aula di Jl. Atmosukarto merupakan pusat aktivitas Jema'at, baik itu aktivitas ibadah maupun mu'amalah. Para anggota Jema'at berpendapat sama mengenai pemaknaan masjid, yaitu sebagai tempat spiritual gathering, sedangkan pemaknaan aula sebagai social gathering. Pemaknaan tersebut sesuai dengan slogan mereka, yaitu "Love for All, Hatred for None". Slogan ini menjadi simbol Jema'at Ahmadiyah, meskipun bukan simbol yang dapat dilihat secara fisik.

\section{REKOMENDASI}

Untuk memaksimalkan konsep perancangan dengan mempertimbangkan memori kolektif Jema'at, maka diperlukan pengembangan konsep desain bangunan serbaguna Jema'at Ahmadiyah Indonesia. Penelitian ini berguna untuk memperdalam aspek kontekstual dalam perencanaan bangunan serbaguna Jema'at Ahmadiyah Indonesia di Piyungan. Hal yang perlu dipertimbangkan kembali adalah pengembalian bentuk material pintu dan jendela bekas menjadi bentuk awal dengan tidak menghilangkan ke khas an dari material tersebut, kemudian pertimbangan penggunaan warna dan bentuk dengan tujuan dapat menghadirkan kembali suasana lama masjid dan aula di Jl. Atmosukarto. 


\section{DAFTAR PUSTAKA}

Alexander, Christopher. 1979. The Timeless Way of Building. Ner York: Oxford University Press.

Amalia, Putri Ayu. (2011). Arsitektur Sebagai Media Pelestarian Memori Kolektif, Studi Kasus: Jewish Museum, Berlin dan Tugu Perjuangan Rakyat Bekasi. Depok: Universitas Indonesia

Baddeley, Alan D. 1999. Essentioals of Human Memory. East Sussex, UK: Psychology Press. Ltd.

Ching, Francis D.K. (1996). Arsitektur: Bentuk Ruang dan Susunannya (Ir. Paulis Hanoto Adjie, Penerjemah). Jakarta: Erlangga

Hayden, Dolores. 1995. The Power of Place. Cambridge, Massachusetts: the MIT Press.

Ihktiyarini, Pratina. (2012). Eksistensi Jema'ah Ahmadiyah Indonesia (JAI) di Yogyakarta Pasca SKB 3 Menteri Tahun 2008. Depok: Universitas Indonesia

Kusno, Abidin. (2009). Ruang Publik, Identitas dan Memori Kolektif: Jakarta PascaSuharto. Yogyakarta: Penerbit Ombak

Lexi, J. Moleong. 2000. Metodologi Penelitian Kualitatif. Bandung: Remaja Rosdakarya

Mairs, Jesica (2015, 30 July). Postmodern architecture: San Cataldo Cemetery by Aldo Rossi. 25 Septermber 2019. https://www.dezeen.com/2015/07/30/san-cataldocemetery-modena-italy-aldo-rossi-postmodernism/

Ricoeur, Paul. (1994). Memory, History, Forgetting. Chicago: The University of Chicago Press

Salkind, Neil J. 2006. Society \& Culture. London: SAGE Publications Ltd.

Sugiyono. 2010. Memahami Penelitian Kualitatif. Bandung: Alfabeta

Surayada, Riena J. (2016). Pusat Komunitas dan Konstentasi Memori Kolektif: Studi Kasus Ruang Publik Terpadu Ramah Anak (RPTRA) Kenanga di Cideng, Jakarta Pusat.Jurnal Sosiologi "Masyarakat" ISSN 0852-8489

Sutrisno, Mudji \& Hendar Punanto. (2005). Teori-teori Kebudayaan. Yogyakarta: Penerbit Kanisius

Sveiven, Megan. (2010, 10 Desember). AD Classics: San Cataldo Cemetery / Aldo Rossi. 25 September 2019. https://www.dezeen.com/2015/07/30/san-cataldo-cemeterymodena-italy-aldo-rossi-postmodernism/

Wattimena, Reza A.A. (2016). Mengurai Ingatan Kolektif Bersama Maurice Halbwachs, Jan Assmann dan Aleida Assmann dalam Konteks Peristiwa 65 di Indonesia. Jurnal Studia Philosophica et Teologica Vol. 16 No.2 ISSN 1412-0674

Wong, Wucius. 1993. Principles of Form and Design. New York: John Wiley \& Sons Inc.Alciatore, D. G. \& Histand, M. B. (2003). Introduction to Mechantronics and Measurement System (2 ed.). New York: McGraw-Hill, Inc. 